\title{
Bir Devlet Hastanesi Acil Servisinden İstenilen Psikiyatri Konsültasyonlarının Değerlendirilmesi
}

\author{
İbrahim Yağcı'®, Yasin Taşdelen²®, Yüksel Kıvrakْ
}

'Kars Harakani Devlet Hastanesi, Psikiyatri Kliniği, Kars, Türkiye ${ }^{2}$ Aydın Devlet Hastanesi, Psikiyatri Kliniği, Aydın, Türkiye ${ }^{3}$ Kafkas Üniversitesi Tıp Fakültesi, Psikiyatri Kliniği Anabilim Dalı, Kars, Türkiye

İbrahim Yağcı, Uzm. Dr. Yasin Taşdelen, Uzm. Dr. Yüksel Kıvrak, Doç. Dr.

Illetişim:

Doç. Dr. Yüksel Kıvrak

Kafkas Üniversitesi Tip Fakültesi, Psikiyatri

Kliniği Anabilim Dalı, Kars, Türkiye

Tel: +905053333999

E-Posta:ykivrak21@gmail.com

\section{ÖZET}

Amaç: Psikiyatrik aciller, bireylerdeki düşünce, duygu ve davranış bozukluklarının hastanın kendisi ya da diğer insanlar için tehdit oluşturduğu ve acil psikiyatrik yardım gerektiren klinik tablolardır. Acil psikiyatrik durumlar şizofreni, psikotik bozukluk, bipolar bozukluk gibi kronik ruhsal hastalıklarda, psikiyatrik belirtilerin görüldüğü tıbbi rahatsızıklarda, zehirlenmelerde, madde kullanımı, ilaç yan etkileri ve psikososyal stres bozuklukları sonrasında da görülmektedir.

Yöntem: Bir yıllık sürede acil servisten psikiyatri konsültasyonu istenilen 241 hastanın tıbbi dosyaları incelenmiştir.

Bulgular: Psikiyatri konsültasyonlarına bakııdığında en sık konulan tanılar sırasıyla anksiyete bozukluğu, depresyon, şizofreni, bipolar bozukluk, uyum bozukluğu, psikotik bozukluk, konversiyon, alkol-madde bağımlılığı ve diğerleridir.

Tartışma: Çalışmamız Anadolu'nun doğusunda yapılan ilk çalışmadır. Acil servisten istenilen psikiyatri konsültasyonlarının incelendiği bu çalışmada elde edilen bulgular, psikiyatrik acillere yönelik hizmetlerin planlanmasında işe yarayabilir. Kronik psikiyatrik hastalıkların tekrar başvuru oranları ve yatış oranlarının yüksek olması koruyucu ruh sağlığı politikaların önemini vurgulamaktadır.

Anahtar sözcükler: Psikiyatri konsültasyonu, acil servis, psikiyatrik hastalıklar

EVALUATION OF THE PSYCHIATRIC CONSULTATIONS REQUIRED FROM A STATE HOSPITAL EMERGENCY SERVICE

\section{ABSTRACT}

Introduction: Psychiatric emergencies are clinical cases in which thoughts, feelings, and behavioral disorders in individuals are threats to the patient himself or other people and require(need) urgent psychiatric help. Psychiatric emergencies are seen in chronic mental illnesses such as schizophrenia, psychotic disorder, bipolar disorder, medical disorders in which psychiatric symptoms are seen, poisonings, substance use, drug side effects and after psychosocial stress disorders.

Methods: The medical records of 241 patients who requested an emergency psychiatric consultation in one year were examined.

Results: When we looked at(Looking at) the psychiatric consultations, the most frequent diagnoses were anxiety disorders, depression, schizophrenia, bipolar disorder, maladjustment, psychotic disorder, conversion, alcoholsubstance dependence and others.

Conclusions: To our knowaldge, this was the first study to be done in the east of Turkey. In this study, in which the psychiatric consultations requested from the emergency department were examined, the findings may be useful in planning services for the psychiatric emergency. The emphasis is placed on the importance of preventive mental health policies, in which recurrent admission rates and high admission rates for chronic psychiatric illnesses are both high.

Keywords: Psychiatric consultation, emergency service, psychiatric disorders 
$\mathbf{H}$ astalar, cerrahi ve dahili branşları ilgilendiren pek çok şikayetle hastane acil birimlerine başkaları tarafından getirtileceği gibi, kendisi de başvurabilir. Psikiyatrik aciller, bireylerdeki düşünce, duygu ve davranış bozukluklarının hastanın kendisi ya da diğer insanlar için tehdit oluşturduğu ve acil psikiyatrik yardım gerektiren klinik tablolardır (1). Acil psikiyatrik muayene; psikiyatrik değerlendirmeyi, belirtilerin psikiyatrik ve tıbbi ayırıcı tanısını, gerektiğinde tanıya yönelik olarak farmakoterapiyi, tıbbi ve cerrahi tedaviyi, psikoterapiyi ve sosyal müdahaleleri içeren uygulamalardan oluşur. Acil psikiyatrik durumlar, şizofreni, psikotik bozukluk, bipolar bozukluk gibi kronik ruhsal hastalıklarda, psikiyatrik belirtilerin görüldüğü tıbbi rahatsızlıklarda, zehirlenmelerde, madde kullanımı, ilaç yan etkileri ve psikososyal stres bozuklukları sonrasında da görülmektedir (2). Ülkemizde acil psikiyatrik hizmetler üniversite ve eğitim araştırma hastaneleri acil servislerinde, psikiyatri dal hastanelerinin acil servislerinde ve devlet hastanelerin acil servislerinde verilmektedir.

Genel hastanelerin acil servislerine yapılan başvuruların \%3-12'si psikiyatrik başvurulardır (3). Acil servise psikiyatrik nedenli başvurularda genellikle kadın-erkek oranı eşittir. Bu başvuruların \%29'unda psikoz, \%25'inde alkol/ madde kullanım sorunları, \%23'ünde majör depresyon, \%13'ünde bipolar bozukluk, \%22'sinde kişilik bozukluğu tespit edilmiştir ve eş tanı da sık görülmüştür (3). Bazı çalışmalarda genel acil servislere başvuran ve ruhsal bozukluğu olan hastaların yaklaşık \%60'ına psikiyatrik tanı konamadığı, psikiyatri konsültasyonunun istenilmediği veya uygun tedavinin düzenlenemediği bulunmuştur $(4,5)$. Psikiyatrik konsültasyon pek çok tıbbi nedenle istenir. Nedenler arasında en sık depresif belirtiler, intihar düşünceleri ya da girişimi, anksiyete, uyum bozuklukları, ruhsal destek gereksinimi, nedeni bulunamayan fiziksel belirtiler, ruhsal durum muayenesinde tespit edilen anormallikler, farmakolojik ilaçların kullanımı ya da yan etkileri konusunda bilgi alma, yeterlilik belirlenmesi bulunur (6).

Acil servise başvuran psikiyatri hastalarının değerlendirildiği çalışmalar bulunmakla beraber, bölgemizde bu konuda yapılan çalışma yoktur. Bu çalışmanın amacı, hastanemiz acil servisine başvuran ve psikiyatri konsültasyonu istenen hastaların demografik özelliklerinin, konulan psikiyatrik tanıların ve konsültasyon isteme nedenlerinin incelenmesidir.

\section{Yöntem}

Kars Harakani Devlet Hastanesi Acil servisine 2016 yılında bir yıllık süre içerisinde başvurmuş olan ve psikiyatri konsültasyonu istenilen hastaların tıbbi dosyaları incelenmiştir. 241 hasta için psikiyatri konsültasyonu istenilmiş olup başvuran hastaların yaşı, cinsiyeti, konsültasyon isteme nedenleri, konsültasyon sonucu konulan psikiyatrik tanıları, yatışları, adli vaka sayıları, başvuru sayıları gibi verilere ulaşılmıştır. Psikiyatrik tanılar, psikiyatrist tarafından yapılan muayene sonucunda konulmuştur. Tıp Fakültesi etik kurulundan çalışmamız için onay alınmıştır.

\section{Istatistik}

Çalışmada elde edilen veriler değerlendirilirken, istatistiksel analizler için SPSS 20.0 for Windows programı kullanıldı. Veriler tanımlayıcı istatistikler ile değerlendirildi.

\section{Bulgular}

Kars Harakani Devlet Hastanesi acil servisinden 2016 yılı içerisinde 241 kere psikiyatri konsültasyonu istenilmiş olup hastaların tümü çalışmamıza alınmıştır. Toplam Acil servisimizde bir yıl içinde bakılan hasta sayısı 200981'dir. Hastanemizde Çocuk ve Ergen Ruh Sağlığı ve Hastalıkları uzman hekimi bulunduğundan dolayı 18 yaş altı hastalar tarafımızca değerlendirilmemekte olup çalışmamıza alınmamıştır. Danışılan hastaların \%69.3'ü $(n=167)$ erkek, \%30.7'si ( $n=74)$ kadındır. Olguların yaş ortalaması 33.4 15.040 'dir. Yaşı en küçük hastamız 18 iken, en büyük hastamız 85 yaşında idi. Erkek olguların yaş ortalaması $32.47 \pm 14.13$ 'dür. Kadın olguların yaş ortalaması $35.49 \pm 16.81$ 'dir. Adli olgular intihar girişimi sonucu başvuran olgulardan ve adli makamlarca resmi yazı ile tarafımıza muayene için gönderilen olgulardan oluşmaktadır. Adli vakalar olguların \%17.4 ( $n=42)^{\prime}$ tür. Adli olguların \%66.7 $(n=28)^{\prime} i$ erkek, \%33.3 ( $\left.n=14\right)^{\prime}$ ü kadındır. Olguların \%85.9'u ( $n=207)$ sivil iken, \%14.6 ( $n=35)^{\prime}$ 's askerdir. İntihar girişimi nedeni ile başvuranların \%65.7 ( $n=23)$ 'si erkek, \%34.3 (12)'ü kadındır. Intihar girişimi nedeni ile başvuranların \%34.3'ü ( $n=12)$ askerdir. İntihar girişiminde bulunanların \%40'ında ( $n=14)$ depresif bozukluk, \%34.3'ünde $(n=12)$ uyum bozukluğu, \%25.7'sinde ( $n=9)$ anksiyete bozukluğu bulunmuştur.

Psikiyatri konsültasyonlarına bakıldığında en sık konulan tanılar sırasıyla anksiyete bozukluğu, depresyon, şizofreni, bipolar bozukluk, uyum bozukluğu, psikotik bozukluk, konversiyon, alkol-madde bağımlılığı ve diğerleridir (Tablo 1). Cinsiyete göre tanılar karşılaştırıldığında erkeklerde en sık konulan tanı şizofreni ve uyum bozukluğu iken kadınlarda ise anksiyete ve depresif bozukluklardır.

Acil serviste değerlendirilen 241 hastanın 87'si (\%36) psikiyatri servisine yatırılarak tedavisi düzenlenmiştir. Yatış 
tanılarına bakıldığında erkeklerde sırasıyla en sık bipolar bozukluk, psikotik bozukluk, şizofreni iken kadınlarda ise sırasıyla bipolar bozukluk, psikotik bozukluk, depresyondur (Tablo 2).

Bir yıl içerisinde tekrarlayan hastaneye başvuru sayılarına bakıldığında en sık şizofreni tanısı konulan hastalar tekrar başvurmuştur (Tablo 3). En sık psikiyatri konsültasyonu isteme nedenlerinin başında eksitasyon ve psikomotor ajitasyon gelmektedir (Tablo 4).

\section{Tablo.1 Konsültasyon sonucunda konulan tanılar}

\begin{tabular}{lcccccc} 
Tanı & Sayı & $\%$ & Erkek Sayı & $\%$ & Kadın Sayı & $\%$ \\
\hline Anksiyete Bozukluğu & 47 & 19.5 & 28 & 16.8 & 19 & 25.7 \\
Bipolar Bozukluk & 29 & 12 & 17 & 10.1 & 12 & 16.2 \\
Depresyon & 39 & 16.1 & 21 & 12.6 & 18 & 24.3 \\
Konversiyon & 14 & 5.8 & 9 & 5.4 & 5 & 6.8 \\
Alkol-Madde & 12 & 5 & 10 & 6 & 2 & 2.7 \\
Psikotik Bozukluk & 19 & 7.9 & 12 & 7.2 & 7 & 9.5 \\
Şizofreni & 33 & 13.7 & 29 & 17.4 & 4 & 5.4 \\
Uyum Bozukluğu & 29 & 12 & 29 & 17.4 & 0 & 0 \\
Zeka Geriliği & 6 & 2.5 & 2 & 1.2 & 4 & 5.4 \\
Obsesif-Kompulsif & 2 & 0.8 & 0 & 0 & 2 & 2.7 \\
Bozukluk & & & & & & \\
Deliryum & 1 & 0.4 & 1 & 0.6 & 0 & 0 \\
Antisosyal Kişilik & 5 & 2 & 5 & 3 & 0 & 0 \\
Bozukluğu & & & & & & \\
Demans & 4 & 1.7 & 3 & 1.8 & 1 & 1.4 \\
Otizm & 1 & 0.4 & 1 & 0.6 & 0 & 0 \\
Toplam & 241 & 100 & 167 & 100 & 74 & 100
\end{tabular}

Tablo 2. Yatış tanıları

\begin{tabular}{lcccccc} 
& \multicolumn{2}{c}{ Toplam } & \multicolumn{2}{c}{ Erkek } & \multicolumn{2}{c}{ Kadın } \\
\hline Tanı & Sayı & $\%$ & Sayı & $\%$ & Sayı & $\%$ \\
\hline Anksiyete Bozukluğu & 9 & 10.3 & 6 & 9,8 & 3 & 11.6 \\
Bipolar Bozukluk & 17 & 19.5 & 10 & 16.4 & 7 & 26.9 \\
Depresyon & 9 & 10.3 & 5 & 8.2 & 4 & 15.4 \\
Konversiyon & 4 & 4.7 & 4 & 6.6 & 0 & 0 \\
Alkol-Madde & 8 & 9.2 & 7 & 11.4 & 1 & 3.8 \\
Psikotik Bozukluk & 13 & 14.9 & 6 & 9.8 & 7 & 26.9 \\
Şizofreni & 13 & 14.9 & 11 & 18 & 2 & 7.7 \\
Uyum Bozukluğu & 10 & 11.6 & 10 & 16.4 & 0 & 0 \\
Zeka Geriliği & 3 & 3.5 & 1 & 1.7 & 2 & 7.7 \\
Otizm & 1 & 1.1 & 1 & 1.7 & 0 & 0 \\
Toplam & 87 & 100 & 61 & 100 & 26 & 100
\end{tabular}

Tablo 3. Hastaların tanılarına göre başvuru sayılarını dağılımı

\begin{tabular}{lccccc} 
& \multicolumn{5}{c}{ Başvuru sayısı } \\
\hline Tanı & $\mathbf{1}$ & $\mathbf{2}$ & $\mathbf{3}$ & $\mathbf{4}$ & $\mathbf{5}$ \\
\hline Bipolar Bozukluk & 16 & 5 & 1 & 0 & 0 \\
Psikotik Bozukluk & 13 & 3 & 0 & 0 & 0 \\
Şizofreni & 10 & 4 & 2 & 1 & 1 \\
Konversiyon & 9 & 1 & 1 & 0 & 0 \\
Uyum Bozukluğu & 22 & 1 & 0 & 0 & 1 \\
Depresyon & 31 & 4 & 0 & 0 & 0 \\
Anksiyete Bozukluğu & 39 & 4 & 0 & 0 & 0
\end{tabular}

\section{Tablo 4. Psikiyatri Konsültasyon isteme Nedenleri}

\begin{tabular}{lcc} 
Konsültasyon İsteme nedeni & Sayı & $\%$ \\
\hline Eksitasyon & 59 & 24.5 \\
Psikomotor Ajitasyon & 46 & 19 \\
Depresif Bulgular & 40 & 16.6 \\
İntihar Girişimi & 35 & 14.5 \\
Bayılma & 14 & 5.8 \\
Maddeye bağlı yoksunluk & 12 & 5 \\
İntihar Düşünceleri & 10 & 4.1 \\
Bilinç Bulanıklı̆ı̆ı & 5 & 2.1 \\
Psikotik Belirtiler & 8 & 3.4 \\
Diğer & 12 & 5 \\
Toplam & 241 & 100
\end{tabular}

\section{Tartışma}

Çalışmamıza alınan olguların büyük kısmını erkekler oluşturmakta olup, en sık konulan tanı grubu duygudurum (bipolar-depresif bozukluklar) bozukluklarıdır. Illimizde erkek nüfusu kadın nüfusuna göre fazladır. Kurumumuz Ardahan, lğdır ve Ağrı illerinden sevk alan bölge hastanesi konumundadır. Kars, Ardahan, Iğdır illerinde bizim hastanemiz dışında kapalı psikiyatri servisi bulunmadığından, kapalı servis ihtiyacı duyulan psikiyatri hastalarının sevk edildiği merkez hastane özelliğini taşımaktadır.

Hastanelerde şiddet giderek artan bir psikososyal bir sorundur (7). Öyküsünde şiddet davranışı olanların, madde kullanımı, kişilik bozukluğu ve psikiyatrik hastalığı bulunan kişilerin şiddet davranışlarında bulunma riskleri yüksektir (8). Çalışmalarda hastaneye başvuru öncesinde veya sırasında psikiyatri hastalarında saldırganlık oranı \%10-25 arasında bulunmuştur (9). Tıbbi açıdan acil olmayan kişilerin acil servise başvuruları hastanelerde hasta sayısının çok fazla artmasına ve bunun sonucunda 
sağlık hizmetlerinin yerine getirilmesinde ciddi sorunlara neden olmaktadır (10). Bu aşırı yoğunluk, hastaların uzun süre beklemesine, acil psikiyatrik olgulara ve ciddi hastalığı olanlara hizmet verilmesinde gecikmeye neden olmaktadır. Acil servise başvuran hastaların henüz tanı konulmamış bir psikiyatrik hastalığı olabileceği, çok yoğun olan acil servislerde gözardı edilebilmektedir. Çalışmamızda sadece acil servisten istenilen psikiyatri konsültasyonları incelenmiş olup psikiyatrik şikayetler ile başvuru oranları bu sayının çok üstündedir. Hastanemizde acil serviste sadece pratisyen hekimler çalışmayıp acil uzmanı hekimlerin devamlı acilde bulunmasından dolayı istenilen konsültasyonlar düşük seviyededir. Fakat istenilen konsültasyonlar sonucu psikiyatri servisine yatış oranları yüksek olduğu için bu hastaların bekletilmeden psikiyatrist tarafından muayene edilmesi gerekmektedir. Psikiyatrik şikayetler ile hastaların başvuru oranlarının çok düşük olmaması nedeni ile muayene sırasında psikiyatrik hastalıklar gözönünde bulundurulması şiddet davranışlarının azalmasına neden olabilir. Bunun sonucunda hizmet kalitesinin artması ve sağlık ekibinin bu tür olaylardan etkilenmesi önlenebilir.

Yapılan çalışmada 2002 yılında bir yıl boyunca genel acil servise başvuranların \%12.9'una bir psikiyatrik bozukluk tanısı konulmuş olup, bu hastaların \%12-25'i psikiyatrik acil tablo olarak değerlendirilmiştir (11). ABD'de 2004 yılında 4.3 milyon olan acil psikiyatri servisine başvuru sayısının, toplam acil servis başvurularının yaklaşık \%5.4'ünü oluşturduğu belirtilmiştir (12). Psikiyatrik belirtiler genellikle organik hastalığa bağlı şikayetler olarak kabul edildiğinden dolayı sisteme hastaların tanıları psikiyatri dışındaki diğer bölümlerin tanıları girilmektedir. Çalışmamıza sadece istenilen psikiyatri konsültasyonları değerlendirildiğinden gerçekte ne kadar psikiyatrik hastalığı olan vakanın başvurduğu bilinmemektedir.

Bir çalışmada acil psikiyatri servisinde en sık konulan tanıların \%26.3 oranında psikoaktif madde kullanımı, \%15.5 şizofreni, \%11.8 manik nöbet, \%10.9 majör depresyon, \%10.9 psikotik olmayan bozukluklar olduğu ortaya konmuştur (13). ABD'de 408 psikiyatrik hastanın değerlendirildiği bir çalışmada, acil servise başvuranlara en sık konulan tanılarının \%66 oranında duygudurum bozukluğu, \%25 oranında psikotik bozukluklar olduğu saptanmıştır (14). Çalışmamızda en sık başvurunun duygudurum bozuklukları (bipolar bozukluklar, depresif bozukluklar) olduğu ikinci sırada psikotik bozukluklar (şizofreni, şizoaffektif bozukluk, atipik psikoz, kısa psikotik bozukluk) olduğu görüldü. Bulgumuz literatür ile uyumludur.
Duygudurum bozukluklarının cinsiyete göre dağılımına baktığımızda erkeklerde daha sık görülmüştür. Literatürde depresif bozuklukların kadınlarda daha sık görüldüğü, bipolar bozukluklarda ise kadın-erkek eşit olarak görüldüğü bildirilmiştir (15). Bulgumuz literatür ile uyumsuz olup bu uyumsuzluğunun nedeni olarak hastaların sadece acil servise başvuran kişilerden oluşması ve bulunduğumuz bölgede kadınların hastaneye psikiyatrik nedenlerle daha az getirilmeleri olabilir.

Çalışmamıza alınan hastaların \%21.6'sinde psikotik bozukluk ve şizofreni tanısı saptandı. Bu oran literatürde \%7-26.9 arasında verilmiştir. Psikotik bozukluk ve şizofreni tanısı konulan olguların \%78.8'i erkekti. Erkeklerde kadınlara göre daha yüksekti. Bulgumuz literatür ile uyumludur. Erkeklerin şizofreni geliştirme riskinin kadınlara göre 1.4 kat daha fazla olduğunu gösterilmiştir (16).

Anksiyete bozuklukları kadınlarda daha yüksek oranda bulunmuş olup, bulgumuz literatür ile uyumludur. Kadınlarda daha fazla görülmesinin nedenleri aile içi şiddet, aile geçimsizliği, ilimizin doğu bölgesinde yer alması ve kadınların üzerlerinde baskının yoğun olması olabilir.

İntihar girişimi ile acile başvuran hastalarla ilgili bir çalışmada, intihar girişiminin daha çok kadınlarda (\%87) görüldüğü saptanmıştır (17). Çalışmamızda intihar girişimi nedeni ile başvuran olguların \%65.7'si erkektir. Literatür ile uyumsuzluğun nedeni başvuran olgularda askerin çok sayıda olması ve askerlerin elverişşiz raporu alabilmek için parasuicidal eylemlerinin çok sayıda olması olabilir. Ayrıca kadınların baskılar nedeni ile adli süreç başlamaması için doğru anamnez vermemesi sonucu intihar girişimi olarak kayıtlarının yapılmaması olabilir.

Çalışmamızın sonuçlarına göre kronik seyirli psikiyatrik hastalığı olan (bipolar bozukluk, psikotik bozukluk, şizofreni) kişilerin tekrarlayan acil başvuru sayıları çoktur. Bunun nedeni ülkemizin neredeyse her yerinde olan fakat ilimizde Toplum ruh sağlığı merkezinin bulunmaması sonucunda hastaların yakın takiplerinin yapılamaması olabilir.

Çalışmamızda değerlendirilen hastaların \%36.1'i psikiyatri servisine yatırılmıştır. Dört yüz sekiz hastanın alındığı başka bir çalışmada, acil psikiyatri servisine başvuran hastaların \%73'ünün hastaneye yatırıldığı bildirilmiştir (14). Çalışmamızda yatış oranlarının daha düşük olmasının nedeni, sadece istenilen konsültasyonların değerlendirilmiş olması olabilir. Çalışmamızda acile başvuran erkek hastalarda yatış oranı \%36.9 iken, kadınlarda bu oran \%35.1 olarak bulundu. Çalışmamızda uyum bozukluğu tanısı 
olan askerlerin sayısının çok olması erkek hastalarda yatış oranlarının kadınlara göre fazla olmasının nedeni olduğunu düşünmekteyiz. Konsültasyon sonucunda yatış oranlarının yüksek olması nedeni ile acile başvuran psikiyatrik belirtilerin tanınması ve psikiyatri konsültasyonlarının istenilmesi önemlidir. Başarılı bir ilk yardım sonradan ortaya çıkabilecek kişinin kendisi veya çevresi ile ilgili oluşabilecek sorunları önleyebilir.

Çalışmamızda psikiyatri konsültasyonu istemenin en sık nedeni eksitasyondur. Bu hastalar bipolar bozukluk, psikotik bozukluk ve şizofreni tanıları olup kronik hastalar olup tedavi-takiplerin sürekli yapılması gerekmektedir. illimizde Toplum ruh sağlığı merkezinin olmaması, hasta takiplerinin yakından yapılamaması sonucunu doğuruyor olabilir. Ayrıca Illimizin nüfusunun büyük kısmının kırsalda yaşaması, yöremizdeki iklim ve coğrafi şartlarının zorlukları hastaların hastaneye başvuru zorlaştırmaları sonucunda tedavilerini düzenli alamamaları nedeni olabilir.

\section{Kaynaklar}

1. Fauman BJ. Other Psychiatric Emergencies. In: Sadock BJ, Sadock VA, Ruiz P, editors. Kaplan and Sadock's Comprehensive Textbook of Psychiatry, 7th ed. Lippincott, Williams and Wilkins, Vol 2; 2000. pp.2040-55.

2. Kısa C, Aydın OD, Cebeci S, Aydemir Ç, Göka A. Acil Psikiyatrik başvuruların ve acil psikiyatrik hizmetlerin değerlendirilmesi. Yeni Symp Derg 2001;39:174-80.

3. Sayıl I. Acil Psikiyatri. Ankara: Ankara Üniversitesi Basımevi; 1987.

4. Polat O, Kabaçam G, Güler İA, Ergişi K, Yıldız A. İbni Sina Hastanesi Acil Servisine başvuran hastaların sürveyans analizi. Türkiye Acil Tıp Derg 2005;5:78-81.

5. Gill JM, Mainous AG, Nsereko M. The effect of continuity of care on emergency department use. Arch Fam Med 2000;9:333-8. [CrossRef]

6. Wise MG, Rundell RJ. Konsültasyon Psikiyatrisi, 1. baskı. Önder E, editör. Tunga T, Verda T, çeviri editörleri. Ankara: Damla Matbaası; 1997.

7. Büyükbayram A, Okçay H. Sağlık Çalışanlarına Yönelik Şiddeti Etkileyen Sosyokültürel Etmenler. J Psychiatr Nurs 2013;4:46-53. [CrossRef]

8. Coşkun S, Tuna Öztürk A. Bakırköy Ruh Sağlığı ve Sinir Hastalıkları Eğitim ve Araştırma Hastanesi Hemşirelerinde Şiddete Maruz Kalma Durumlarının İncelenmesi. Maltepe Üniv Hem Bilim Sanat Derg 2010;3:16-23. Erişim: https://www.researchgate. net/publication/233727291_Bakirkoy_Ruh_Sagligi_ve_Sinir_ Hastaliklari_Egitim_ve_Arastirma_Hastanesi_Hemsirelerinde_ Siddete_Maruz_Kalma_Durumlarinin_Incelenmesi

9. Kayatekin ZE, Maner F, Abay E, Saygılı S, Şener Ai. Ruh hastalarında homisidal saldırganlık. Düşünen Adam 1991;4:22-7. Erişim: http:// www.dusunenadamdergisi.org/ing/DergiPdf/DUSUNEN_ADAM_ DERGISI_d10bc0b3885448058c7bdeb4458376ac.pdf
Çalışmamız Anadolu'nun doğusunda yapılan ilk çalışmadır. Acil servisten istenilen psikiyatri konsültasyonlarının incelendiği bu çalışmada elde edilen bulgular, psikiyatrik acillere yönelik hizmetlerin planlanmasında işe yarayabilir. Kronik psikiyatrik hastalıkların tekrar başvuru oranları ve yatış oranlarının yüksek olması koruyucu ruh sağlığı politikaların önemini vurgulamaktadır.

Bu çalışmanın önemli kısıtııığı sadece acil servisten istenilen psikiyatri konsültasyonlarının incelenmesidir. Sonuçlar acile başvuran tüm hastalar hakkında bilgi vermemektedir. Bir diğer kısıtlılığı ise olguların verilerine hastanenin kayıt sisteminden ulaşılmış olup sosyodemografik veriler eksiktir. Prospektif bir çalışma ile acil servise başvuran hastaların psikiyatrik şikayetleri dikkate alınarak gözardı edilmemesi sonucunda acil servise başvurularda psikiyatrik hastalıkların tanıları ve oranları kesin olarak tespit edilebilir.

10. Andrulis DP, Kellermann A, Hintz EA, Hackman BB, Weslowski VB. Emergency department and crowding in United States teaching hospitals. Ann Emerg Med 1991;20:980-6. [CrossRef]

11. Pajonk FG, D'Amelio R. Psychosocial emergencies-agitation, aggression and violence in emergency and search and rescue services. Anasthesiol Intensivmed Notfallmed Schmerzther 2008;43:514-21. [CrossRef]

12. Riba MB, Ravindranath D. Acil Psikiyatri Klinik El Kitabı. Şar V, çeviri editörü. İstanbul: Medikal; 2011.

13. Santos ME, do Amor JA, Del-Ben CM, Zuardi AW. Psychiatric emergency service in a university general hospital: a prospective study. Rev Saude Publica 2000;34:468-74. [CrossRef]

14. Douglass AM, Luo J, Baraff LJ. Emergency medicine and psychiatry agreement on diagnosis and disposition of emergency department patients with behavioral emergencies. Acad Emerg Med 2011;18:368-73. [CrossRef]

15. Okan İbiloğlu A, Çayköylü A. Bipolar I, bipolar II ve majör depresif bozuklukta ayrışan sosyodemografik, klinik ve mizaç özellikleri. Türk Psikiyatri Derg 2011;22:159-65. Erişim: http://www.turkpsikiyatri. com/pdf/c22s3/159-165.pdf

16. Mc Grath J, Saha S, Welham J, El Saadi O, MacCauley C, Chant D. A systematic review of the incidence of schizophrenia: the distrubition of rates and the influencce of sex, urbanicity, migrant status and methodology. BMC Med 2004;2:13. [CrossRef]

17. Tel H, Uzun S. Intihar girişimi ile acil servise başvuran hastaların sosyal destek ve stresle baş etme durumları. Anadolu Psikiyatri Derg 2003;4:151-58. 